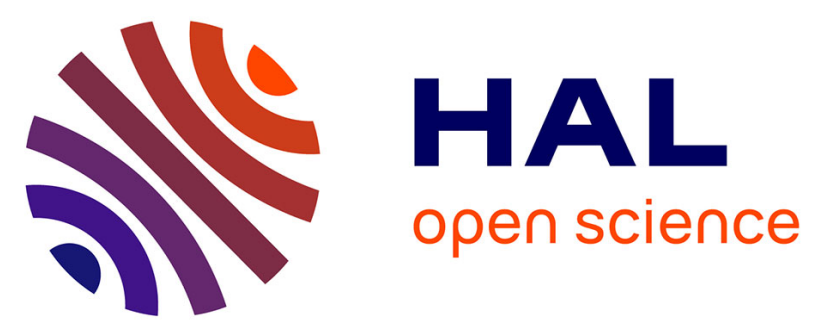

\title{
Phenotypic Characterization of Insertion Mutants of the Human Immunodeficiency Virus Type 1 Gag Precursor Expressed in Recombinant Baculovirus-Infected Cells
}

Nathalie Chazal, Christian Carrière, Bernard Gay, Pierre Boulanger

\section{- To cite this version:}

Nathalie Chazal, Christian Carrière, Bernard Gay, Pierre Boulanger. Phenotypic Characterization of Insertion Mutants of the Human Immunodeficiency Virus Type 1 Gag Precursor Expressed in Recombinant Baculovirus-Infected Cells. Journal of Virology, 1994, 68 (1), pp.111-122. hal-02147257

\author{
HAL Id: hal-02147257 \\ https://hal.science/hal-02147257
}

Submitted on 7 Jun 2019

HAL is a multi-disciplinary open access archive for the deposit and dissemination of scientific research documents, whether they are published or not. The documents may come from teaching and research institutions in France or abroad, or from public or private research centers.
L'archive ouverte pluridisciplinaire HAL, est destinée au dépôt et à la diffusion de documents scientifiques de niveau recherche, publiés ou non, émanant des établissements d'enseignement et de recherche français ou étrangers, des laboratoires publics ou privés. 


\title{
Phenotypic Characterization of Insertion Mutants of the Human Immunodeficiency Virus Type 1 Gag Precursor Expressed in Recombinant Baculovirus-Infected Cells
}

\author{
NATHALIE CHAZAL, CHRISTIAN CARRIÈRE, BERNARD GAY, AND PIERRE BOULANGER* \\ Laboratoire de Virologie and Pathogénèse Moléculaires (CNRS URA 1487), Faculté de Médecine, \\ Institut de Biologie, 34060 Montpellier, France
}

Received 21 July 1993/Accepted 23 September 1993

\begin{abstract}
A panel of 28 insertion mutants of the human immunodeficiency virus type 1 (HIV-1) Gag precursor $\left(P r 55^{G a g}\right)$ was constructed by linker-insertion mutagenesis and expressed in recombinant baculovirus-infected insect cells. One set of 14 mutants carried the normal $\mathbf{N}$-myristylation signal; the other set constituted their non-N-myristylated counterparts. The mutants were characterized with respect to (i) assembly and extracellular release of membrane-enveloped budding Gag particles, (ii) intracellular assembly and nuclear transport of Gag cores, (iii) specific processing of Pr55 ${ }^{\text {Gag }}$ by HIV-1 protease in vivo, and (iv) binding of Pr55 ${ }^{\text {Gag }}$ to an HIV-1 genomic RNA probe in Northwestern blotting. Insertions within the region between amino acid residues 209 and 334 in the CA domain appeared to be the most detrimental to Gag particle assembly and release of Gag into the external medium, whereas a narrower window, between residues 209 and 241, was found to be critical for secretion of soluble Pr55 ${ }^{\text {Gag }}$. Differences in Pr55 ${ }^{\text {Gag }}$ processing in vivo and RNA binding in vitro between $\mathrm{N}$-myristylated and non-N-myristylated Gag mutants suggested a major conformational role for the myristylated $\mathbf{N}$ terminus of Gag precursor. In coinfection experiments using wild-type Gag- and mutant Gag-expressing recombinants, a transdominant negative effect on Gag particle assembly and release was observed for insertions located in two separate domains, the matrix and nucleocapsid.
\end{abstract}

Three major structural proteins of the human immunodeficiency virus type 1 (HIV-1) virion originate from the specific cleavage of a 55,000-Da polyprotein precursor $\left(\operatorname{Pr} 55^{\mathrm{Gag}}\right)$ by the virus-coded protease: the p17 matrix (MA), p24 capsid (CA), and p15 nucleocapsid (NC) proteins (for reviews, see references 6,12 , and 44). In previous studies, it has been shown that recombinant $\operatorname{Pr} 55^{\mathrm{Gag}}$ synthesized in baculovirus-infected insect cells is capable of self-assembly. $\mathrm{N}$-myristylated Pr55 $5^{\mathrm{Gag}}$ forms membrane-enveloped virus-like particles which are released into the external medium by budding from the plasma membrane, while assembly of non-N-myristylated Pr55 $5^{\text {Gag }}$ occurs intracellularly $(8,13,19,30,34)$. The carboxy-terminal domain $\mathrm{p} 6$ of the NC protein has been found to be dispensable for intracellular assembly of non-N-myristylated Gag core-like particles and for budding and extracellular release of $\mathrm{N}$ myristylated Gag particles by insect cells $(34,35)$, in contrast to mammalian cells (14).

Deletion of the p15 domain from non-N-myristylated Gag precursor (Pr41 Gag) abolished its intracellular assembly (34). For N-myristylated $\mathrm{Pr} 41^{\mathrm{Gag}}$, the downstream boundary of the Gag precursor sequence required for particle budding has been mapped to the p24-p25 junction (21). Two substitution mutations in the carboxy-terminal moiety of the p24 domain, L268P and L322S, have been found to be deleterious for the intracellular assembly function of non-N-myristylated Gag precursor. However, only the L268P mutation abolished the budding of $\mathrm{N}$-myristylated Gag particles and the secretion of soluble Gag precursor (18). This finding suggested that discrete subdomains of the HIV-1 Gag precursor were involved at

* Corresponding author. Mailing address: Laboratoire de Virologie and Pathogénèse Moléculaires, Faculté de Médecine de Montpellier, 34060 Montpellier Cedex, France. Phone: (33) 676057 38. Fax: (33) 67410246. various degrees in the self-assembly and budding processes of virus-like particles.

To further characterize the polypeptide domains of HIV-1 Gag precursor involved in the mechanisms of assembly of virus capsids and release of membrane-enveloped, budding Gag particles by the infected cells, we used a suppressor-linker insertional method (25) to introduce small in-frame 12-bp insertions into HIV-1 gag DNA. Two sets of 14 insertion mutants each were generated; one set of mutants carried the normal $\mathrm{N}$-myristylation signal, and the other set constituted their non-N-myristylated counterparts. Three insertion mutants were thus obtained in the p17 domain (in 40 , in 100 , and in 120 ), seven were obtained in the p 24 domain (in 143, in 184, in 209, in 241, in 334, in 341, and in 357), one was obtained in the p25 additional sequence (in374), two were obtained in the p7 domain (in 426 and in 438), and one was obtained in the p6 domain (in 462). The resulting phenotype of the Pr55 Gag mutants expressed in the baculovirus system was characterized with respect to the following criteria: (i) extracellular release of membrane-enveloped Gag particles and of soluble Gag, (ii) intracellular assembly and subcellular location of Gag cores, (iii) processing in vivo by the coexpressed HIV-1 protease, and (iv) binding to a viral genomic RNA probe.

An essential sequence for Gag particle assembly and budding, as well as for soluble Gag secretion, was mapped to the C-terminal two-thirds of the capsid domain. Furthermore, a novel conformational function was found for the myristyl group at the $\mathrm{N}$ terminus of the Gag precursor, in addition to its role in membrane targeting (15). Insertion mutants of Pr55 ${ }^{\mathrm{Gag}}$ which were assembly defective when expressed in the non-Nmyristylated form were restored to wild-type (WT) particle budding phenotype when their insertions were placed in the $\mathrm{N}$-myristylated Gag polypeptide backbone. This observation confirmed previous results obtained with deletion (21) and substitution (18) mutants. Conversely, RNA binding activity of 
TABLE 1. Sequences of HIV-1 Gag insertion mutants

\begin{tabular}{|c|c|c|c|c|c|c|}
\hline \multirow{2}{*}{ Mutant" } & \multirow{2}{*}{$\begin{array}{r}\text { Site of } \\
\text { insertion }\end{array}$} & \multirow{2}{*}{$\begin{array}{l}\text { Nucleotide } \\
\text { position }\end{array}$} & \multirow{2}{*}{$\begin{array}{c}g a g \\
\text { codon }\end{array}$} & \multirow{2}{*}{$\begin{array}{l}\text { Domain } \\
\text { affected }^{d}\end{array}$} & \multicolumn{2}{|c|}{ aa sequence $e^{\prime}$} \\
\hline & & & & & From & To \\
\hline $\operatorname{in} 40$ & Alu I & 452 & 40 & p17 & EL & ELEFQL \\
\hline in 100 & Alu $\mathrm{I}$ & 630 & 100 & p17 & $\overline{A L}$ & AGIPAL \\
\hline in 120 & $P v u \mathrm{II}$ & 690 & 120 & p17 & $\mathrm{AD}$ & AGIPAD \\
\hline in 143 & Rsal & 760 & 143 & p24 & $\mathrm{VH}$ & VWNSRH \\
\hline in 184 & DraI & 883 & 184 & p24 & $\mathrm{LN}$ & FWNSRN \\
\hline in 209 & Alu $\mathrm{I}$ & 957 & 209 & p24 & AA & AGIPAA \\
\hline in 241 & Rsa $\mathrm{I}$ & 1055 & 241 & p24 & ST & SLEFQT \\
\hline in 334 & DraI & 1333 & 334 & p24 & LK & FWNSRK \\
\hline in 341 & Alu I & 1353 & 341 & p24 & AT & AGIPAT \\
\hline in 357 & HaeIII & 1402 & 357 & p24 & $\mathrm{GH}$ & GWNSSH \\
\hline in 374 & Alu $\mathrm{I}$ & 1452 & 374 & $\mathrm{p} 25$ & AT & AGIPAT \\
\hline in 426 & RsaI & 1610 & 426 & p7 & $\mathrm{CT}$ & CLEFQT \\
\hline in 438 & HaeIII & 1646 & 438 & p7 & WP & WLEFQP \\
\hline in 462 & Alu I & 1753 & 462 & p6 & $\mathrm{SF}$ & SWNSSF \\
\hline
\end{tabular}

"Each was constructed in its $\mathrm{N}$-myristylated and non- $\mathrm{N}$-myristylated versions.

${ }^{b}$ The base pair preceding the inserted sequence is numbered from the cap site of the HIV-1 $1_{\mathrm{Bru}}$ genome sequence (42).

" The position of the mutation is indicated by the codon in the gag gene sequence immediately preceding or modified by the insertion.

"The p17 matrix, p24 and p25 capsid, p15 and p7 nucleocapsid, and p6 domains were defined by HIV-1 protease cleavage at the following peptide bonds: Y-132-P-133, L-363-A-364, M-377-M-378, and F-448-L-449 (28).

"The amino acids (aa) involved by the insertion are indicated by the single-letter code, and the inserted tetrapeptides are indicated in boldface.

Gag mutants was restored to WT levels when the N-terminal myristylation signal was deleted. Hence, the N-myristyl group could likely function as a global second-site suppressor of mutations (11) in gag which affect the conformation of the Gag polyprotein molecule as a whole.

\section{MATERIALS AND METHODS}

Virus and cells. Two parental recombinants of Autographa californica nuclear polyhedrosis virus (AcNPV), Gag12myr ${ }^{+}$ and G2A, were used as parental clones for insertion mutagenesis. Gag12 $\mathrm{myr}^{+}(34,35)$ expresses the WT form of $\mathrm{N}$ myristylated full-length Gag precursor $\left(\mathrm{GagPr} 55 \mathrm{myr}^{+}\right)$. In G2A, a G-to-C substitution was introduced by oligonucleotidedirected mutagenesis at the second nucleotide of the second codon in the gag sequence, resulting in a GGT (glycine)-toGCT (alanine) mutation. As a consequence of the loss of the $\mathrm{N}$-myristylation signal, G2A expressed an N-myristylated-minus mutant form of $\operatorname{Pr}^{55^{\mathrm{Gag}}}\left(\mathrm{GagPr} 55 \mathrm{myr}^{-}\right)$. Gag mutant Och184 was obtained by inserting a TAA stop codon at position 184 in the Gag sequence, resulting in a C-truncated Gag product consisting of the entire matrix domain and the downstream 50 amino acids belonging to the capsid domain. The gag gene product expressed by recombinant Och184 was a protein of 183 residues and $22 \mathrm{kDa}$ in apparent molecular mass. WT and mutant Pr55 ${ }^{\mathrm{Gag}}$ were produced as recombinant proteins in Spodoptera frugiperda Sf9 cells maintained in Grace's medium supplemented with $10 \%$ fetal calf serum. Recombinants AcNPV-PR107 and AcNPV-PR77 contain a synthetic gene for an active form and a carboxy-terminally deleted, inactive form of the HIV-1 protease $(18,39)$, respectively. Both are expressed under the control of the polyhedrin promoter. In coinfection experiments, Sf 9 cells were first infected with the recombinant expressing the Gag substrate at a multiplicity of infection (MOI) of 20 PFU per cell for $1 \mathrm{~h}$ at room temperature, after which the virus inoculum was removed and the cells were further incubated for $1 \mathrm{~h}$ with the second recombinant expressing the HIV-1 protease, at an MOI of $10 \mathrm{PFU}$ per cell. Cells were harvested at $24 \mathrm{~h}$ postinfection (p.i.), and cell lysates were analyzed for Gag precursor processing.
Suppressor-linker insertional mutagenesis. Mutagenesis was conducted on a pUC18 plasmid containing the coding sequence for the gag gene ( $\left.\mathrm{p} 18^{g a g}\right)$. The insertion mutations were generated by the strategy of Lobel and Goff (25), which consists of introducing small in-frame 12-bp insertions into genes. The $18^{g a g}$ plasmid was subjected to partial restriction nuclease digestion in separate reactions, with the following blunt cutters: AluI, DraI, HaeIII, PvuII, and Rsa (Boehringer, Mannheim, Germany). The linearized molecules were purified by agarose gel electrophoresis, blunt-end ligated to the $P v u$ II suppressor-linker DNA fragment, and transfected into Escherichia coli $\mathrm{CC} 114$. Transformants were selected on MacConkey lactose agar (Difco Laboratories). Plasmids containing insertions were digested with $E c o$ RI and recircularized. The sites of insertion were mapped by restriction enzyme digestion. Each insertion in the gag gene was isolated by digestion at unique restriction sites and reinserted into the corresponding sites of an intermediate baculovirus plasmid containing the coding sequence for the N-myristylated (WT) or non-N-myristylated (G2A) form of Pr55 ${ }^{\mathrm{Gag}}$, cloned downstream of the polyhedrin promoter. Each mutant gag-containing plasmid was recombined with DNA from AcNPV as previously described $(34,35)$. Recombination with the first type of plasmid vector generated a set of insertion mutants of N-myristylated Pr55 Gag, whereas recombination with the second type of plasmid gave rise to their non- $\mathrm{N}$-myristylated equivalents.

Nomenclature. Each mutant name indicates the location of its insertion, numbered according to the codon in the gag sequence which was immediately preceding or modified by the insertion; e.g., in $40 \mathrm{myr}^{+}$indicates that codons 40 and 41 of Pr55 ${ }^{\mathrm{Gag}}$, which code for glutamic and leucine residues, respectively, were separated by an inserted tetrapeptide sequence in the mutant (E)-40-LEFQ-L-41; Table 1). The non-N-myristylated counterpart of each GagPr55myr ${ }^{+}$insertion mutant is indicated by the suffix "myr" " following its number, e.g., in $40 \mathrm{myr}^{-}$.

EM. Sf 9 cells infected at an MOI of 10 PFU per cell were harvested for electron microscopic (EM) processing at $48 \mathrm{~h}$ p.i. The cell pellets were fixed with $2.5 \%$ glutaraldehyde in $0.1 \mathrm{M}$ phosphate buffer ( $\mathrm{pH} 7.5)$, postfixed with osmium tetroxide $\left(2 \%\right.$ in $\left.\mathrm{H}_{2} \mathrm{O}\right)$, and treated with tannic acid $\left(0.5 \%\right.$ in $\left.\mathrm{H}_{2} \mathrm{O}\right)$. 
After dehydration, the specimens were embedded in Epon-812 (Fulham, Latham, N.Y.). Sections were stained with $2.6 \%$ alkaline lead citrate and $0.5 \%$ uranyl acetate in $50 \%$ ethanol. Specimens were poststained with $0.5 \%$ uranyl acetate and examined under a Hitachi-H7100 EM.

Electrophoretic and immunological analyses. Protein samples were electrophoresed in sodium dodecyl sulfate (SDS)$12.5 \%$ polyacrylamide gels (acrylamide/bisacrylamide ratio of $50: 0.8$ ), using a discontinuous buffer system (22). The proteins were electrically transferred from the SDS-gel onto nitrocellulose membranes (Hybond-ECL [enhanced chemiluminescence]; Amersham) at $180 \mathrm{~mA}$ for $90 \mathrm{~min}$, using a semidry system (Cambridge Electrophoresis, Ltd., Cambridge, England). After saturation in $5 \%$ skimmed milk in $20 \mathrm{mM}$ Tris- $\mathrm{HCl}$ (pH 7.5)-150 mM NaCl-0.05\% Tween 20 (TBS-T buffer) for $1 \mathrm{~h}$ at room temperature, $\operatorname{Pr} 55^{\mathrm{Gag}}$ was detected on blots by successive incubations with anti-Gag antibody, alkaline phosphatase-labeled anti-immunoglobulin $G$ conjugate (1:1,000; Sigma), and nitroblue tetrazolium-5-bromo-4-chloro3-indolyl phosphate toluidinium cosubstrate-substrate (Boehringer) for color development (18). The primary anti-Gag antibodies were mouse monoclonal antibody (MAb) directed against Pr55-p24 (Epiclone 5001; Epitope Inc., Beaverton, Oreg.), mouse MAb anti-Pr55-p17 (Epiclone 5003), rat MAb anti-p6 (40), and homemade rabbit serum against $\operatorname{Pr} 55^{\mathrm{Gag}}$. They were used at a dilution of 1:1,000 to 1:1,500 in TBS-T for $16 \mathrm{~h}$ at room temperature.

Gag secretion. $\operatorname{Pr} 55^{\mathrm{Gag}}$ has been shown to be released in the extracellular medium in two different forms, membrane-enveloped virus-like particles and nonassembled, soluble Gag polyproteins (35). Total secretion of Pr55 Gag (soluble plus particulate) was immunologically assayed on unfractionated cell culture medium collected at $48 \mathrm{~h}$ p.i. and clarified by centrifugation at $8,000 \times g$ for $5 \mathrm{~min}$, using a protein blotting technique. The amount of Pr55 ${ }^{\mathrm{Gag}}$ released as budding particles was estimated by the same technique, performed on pelletable fraction of Pr55 Gag, obtained by a two-step sucrose gradient centrifugation method (37). Aliquots of infected cell culture supernatants were analyzed by SDS-polyacrylamide gel electrophoresis (PAGE), and proteins were transferred onto Hybond-ECL membranes as described above. Two of our insertion mutations were found to disrupt the Pr55 ${ }^{\mathrm{Gag}}$ epitope recognized by Epiclone 5001, whereas none modified its reactivity toward Epiclone 5003, which is specific for the p17 domain. Hybond-ECL membranes were therefore stepwise reacted with MAb Epiclone 5003 (1:1,000, overnight at room temperature), horseradish peroxidase-labeled anti-mouse immunoglobulin $\mathrm{G}$ conjugate (1:1,000; Amersham), and chemiluminescent substrate (Luminol; Amersham). Immunoblots were exposed to radiographic films (Hyperfilm-ECL; Amersham) for different lengths of time to prevent misevaluations of overexposed bands, and the luminograms were scanned at 610 $\mathrm{nm}$, using an automatic scanner (REP-EDC densitometer system; Helena Laboratories, Beaumont, Tex.). The values obtained for secreted mutant $\operatorname{Pr} 55^{\mathrm{Gag}}$ were calculated from the intensity of their signals relative to that of WT GagPr55myr ${ }^{+}$. ECL blots were calibrated with samples of Gag12myr-infected cell supernatant, the total GagPr55myr ${ }^{+}$concentration of which had been previously determined by antigen capture enzyme-linked immunosorbent assay as previously described (35). WT Pr55 ${ }^{\mathrm{Gag}}$ concentration, expressed as micrograms per milliliter of culture medium ( $1 \mathrm{ml}$ corresponding to the supernatant of $10^{6}$ cells), usually ranged between 20 and $30 \mu \mathrm{g} / \mathrm{ml}$ per $10^{6}$ cells in Gag12myr-infected cell supernatants.

DNA sequence analysis. The fragment of recombinant baculovirus DNA carrying the gag insertion was amplified by PCR, using oligonucleotide primers hybridizing to sequences upstream and downstream of the mutation. Oligonucleotides were synthesized by Eurogentec (Seraing, Belgium). PCR fragments were sequenced by a dideoxynucleotide method (Sequenase sequencing kit; United States Biochemical Corp., Cleveland, Ohio) under the conditions recommended by the supplier.

Viral RNA binding. Each insertion mutant of Pr55 ${ }^{\mathrm{Gag}}$ was assayed for RNA binding capability by the Northwestern blotting technique developed by Luban and Goff (26). The SacI-XmnI fragment from the gag gene DNA (nucleotides 221 to 815 from the cap site in the HIV-1 $1_{\text {Bru }}$ sequence [42]), which contained the encapsidation signal $(7,17,24)$, was cloned between the SacI and HincII sites of pBluescript II KS( - ). ${ }^{32} \mathrm{P}$-labeled RNA probe was obtained by in vitro transcription of the resulting plasmid linearized at the internal XmnI site at nucleotide 381, using an RNA transcription kit (Stratagene). The genomic RNA probe, transcribed from the T7 promoter, corresponded to the 5'-terminal region (SacI-XmnI, nucleotides 221 to 381 ), spanning the splice donor site and the start of the gag gene, as used by Jowett et al. (21). Nonspecific RNA probe, transcribed from the T3 promoter on the complementary strand, corresponded to the XmnI-XmnI fragment (nucleotides 815 to 381 ). After SDS-PAGE and electrical transfer to ECL membranes, proteins of whole cell lysates were renatured by immersing the membrane in $30 \mathrm{mM}$ HEPES ( $N$-2-hydroxyethylpiperazine- $N^{\prime}$-2-ethanesulfonic acid)-KOH buffer $(\mathrm{pH}$ 7.5)-200 mM KCl-10 $\mu \mathrm{M} \mathrm{ZnCl}_{2}-2 \mathrm{mM}$ dithiothreitol containing $500 \mu \mathrm{g}$ of heparin per $\mathrm{ml}$ (NW buffer). Blots were reacted with $5 \times 10^{5} \mathrm{cpm}$ per blot (20 to $25 \mathrm{ng}$ of RNA) for $1 \mathrm{~h}$ at room temperature in NW buffer and autoradiographed.

\section{RESULTS}

Construction of linker-insertion mutations in GagPr55. In-frame insertions of $12 \mathrm{bp}$ were introduced into the DNA sequence of the HIV-1 gag gene, at sites generated by the blunt cutters AluI, DraI, HaeIII, PvuII, and RsaI (25). Fourteen insertion mutants in the N-myristylated recombinant GagPr55 were thus generated, and the equivalent insertions were similarly constructed in the non- $\mathrm{N}$-myristylated form of recombinant Pr55 Gag. Table 1 shows the nature of the inserted amino acids and the locations of the mutation sites in the gag gene sequence. Insertion mutants were isolated as follows: three in the p17 matrix domain (in 40, in 100 , and in 120), seven in the p24 capsid (in 143, in 184, in 209, in 241, in 334, in 341, and in 357), one in the p1.5 extra peptide between the p25 and p24 cleavage sites (in 374), two in the p7 nucleocapsid (in 426 and in 438), and one in the p6 domain (in462).

Mutant in 120 had its insertion within a region of high homology between membrane-associated proteins of many RNA viruses other than retroviruses (4), corresponding to residues 119 to 128 in the $\mathrm{Gag}_{\mathrm{Bru}}$ sequence (42). Insertions in 40 and in 120 were located in regions of the MA domain with a high probability of helical conformation, according to structure predictions (2). Insertions at positions in 184, in 209, in 241, in 334, and in 341 in the CA domain involved residues which have been shown to be highly conserved in all retrovirus and several picornavirus capsid proteins (3). Two of them, in 241 and in 334, were located on each side of the major homology region of retrovirus capsid proteins spanning residues 285 to 304 in HIV-1 Pr55 Gag, which constitutes part of the postulated puff $(3,23)$ and also corresponds to the assembly domain AD3 of Gag (44). In the p7 domain, the in 426 tetrapeptide was inserted at the carboxylic side of the last cysteine residue implicated in the second zinc finger, and the in 438 insertion lay 
downstream of the second zinc finger, on the carboxylic side of the second tryptophan residue of $\mathrm{p} 7$. The insertion in the $\mathrm{p} 6$ domain (in462) was located immediately downstream of the conserved PTAPP sequence at residues 455 to 459 (29).

Expression and proteolytic processing of mutant Gag precursors. Pr $55^{\text {Gag }}$ was found to be expressed at similar levels in all but one insertion mutant-infected cell cultures. With both $\mathrm{N}$-myristylated and non-N-myristylated forms of in 40 mutant, a gag gene product of about $39 \mathrm{kDa}$ was detected as the major anti-Gag antibody-reacting signal. Only trace amounts of Pr55 $5^{\mathrm{Gag}}$ were visible at all stages of infection, and pulse-chase experiments suggested a rapid cleavage of newly synthesized or nascent $\operatorname{Pr} 55^{\text {(iag }}$ by host cell proteases (data not shown). Epitope analysis with MAbs directed against the p17 and p6 domains showed that the 39-kDa species contained the carboxy-terminal region p6, not p17 (see Fig. 4). This finding implied that the proteolytic cleavage occurred preferentially at or near the p17-p24 junction. None of the insertion mutants except in 209 showed any particular cytopathic effect other than the late cytopathic effect induced by the baculovirus itself. Two insertions, in 334 and in 341, completely destroyed the reactivity of $\operatorname{Pr} 55^{\text {(iag }}$ with MAb Epiclone 5001 (not shown), which allowed us to map its epitope to a sequence spanning residues 334 to 341 (LKALGPAA). All mutant Pr55 ${ }^{\text {Gag }}$ but one, in 334, showed an electrophoretic mobility similar to that of WT Pr55 ${ }^{\text {Gag }}$ expressed by Gag $12 \mathrm{myr}^{+}$; Pr55 ${ }^{\text {Gag }}$ expressed by in 334 migrated slightly more slowly than WT Pr55 5 ag (Fig. 1).

Gag polyprotein is the natural substrate for HIV-1 protease, which specifically cleaves it into p17, p24-p25 doublet, and p15 by hydrolysis of the Tyr-Pro (132-133), Leu-Ala (363-364), and Met-Met (377-378) bonds (28). Possible conformational alterations of the Pr55 ${ }^{\text {ciag }}$ insertion mutants were investigated by their susceptibility to HIV-1 protease coexpressed in vivo. Sf9 cells were coinfected with separate recombinants, one expressing gag and the other expressing a synthetic gene for HIV-1 protease (39), both under the control of the polyhedrin promoter (AcNPV-PR107 [18]). In parallel, as a control for nonspecific Gag processing by host cell proteases, cell cultures were doubly infected with each Gag recombinant and AcNPVPR77, a recombinant expressing an inactive, carboxy-truncated form of HIV-1 protease (33a). Pr55 ${ }^{\text {Gag }}$ cleavage was assayed by SDS-PAGE and immunoblotting analysis. A certain degree of spontaneous clcavage of WT and mutant Pr55 $5^{\text {Gag }}$ by host cell enzymes occurred at late times of coinfection with AcNPVPR77, and anti-Gag antibody-reacting products migrating at 47 and $41 \mathrm{kDa}$ were always visible (not shown) $(18,35)$. This proteolytic effect was observed at similar levels with both $\mathrm{N}$-myristylated and non-N-myristylated forms of Pr55 $5^{\text {Gag }}$.

In coinfection with the recombinant expressing the active protease, the expected specific p17 and p24-p25 Gag products were visible in most patterns, and their electrophoretic mobility was consistent with proteins carrying a four-amino-acid insertion (Fig. 1). Four mutants, in $40 \mathrm{myr}^{+}$, in $209 \mathrm{myr}^{+}$(Fig. 1a), in $40 \mathrm{myr}^{-}$, and in $241 \mathrm{myr}$ (Fig. 1b), showed a cleavage pattern significantly different from the parental one, with almost no detectable p25-p24 doublet. In in $40 \mathrm{myr}^{+}$, in $40 \mathrm{myr}^{+}$, and in $241 \mathrm{myr}^{+}$, a major band of about $39 \mathrm{kDa}$ appeared to resist further protease cleavage. The absence of the specific p25-p24 doublet in these mutant patterns suggested that Gag-p39 was not a preferred substrate for HIV-1 protease in vivo and that only $\operatorname{Pr} 41^{\text {Gag }}$, resulting from an initial cleavage of Pr55 $5^{\text {Gag }}$ at the capsid-nucleocapsid junction, was able to generate the p24-p25 capsid proteins. Comparisons of the cleavage patterns of $\mathrm{N}$-myristylated and non- $\mathrm{N}$-myristylated forms of $\operatorname{Pr} 55^{\mathrm{Gag}}$ seemed to indicate that all of the $\mathrm{N}$ myristylated forms of recombinant $\operatorname{Pr} 55^{\text {Gag }}$ were processed

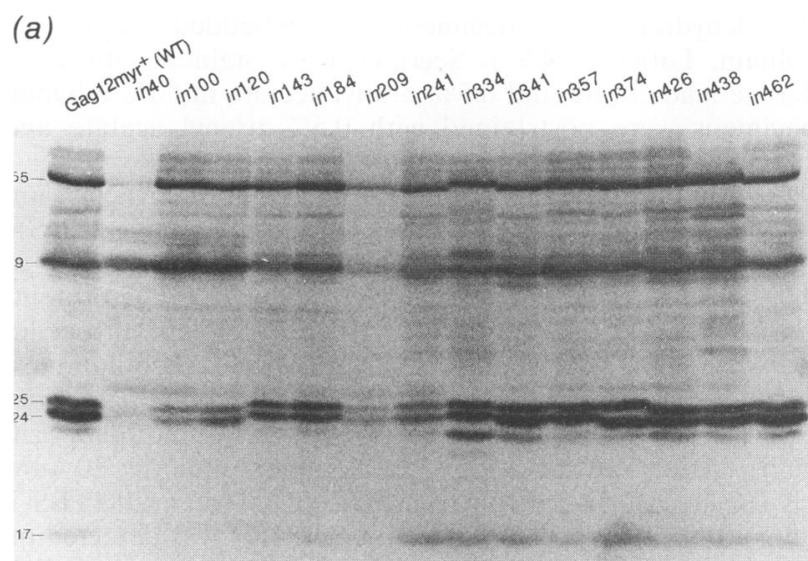

(b)
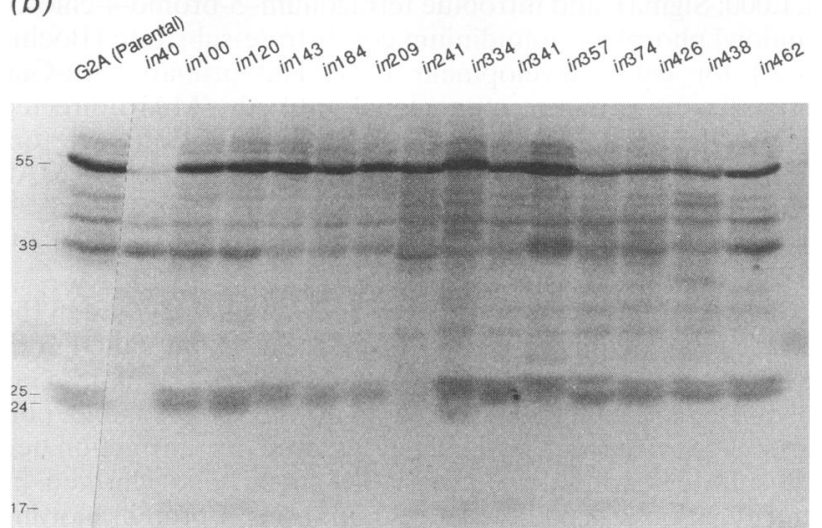

FIG. 1. Immunoblotting patterns of Sf 9 cell extracts coinfected with HIV-1 Gag-AcNPV recombinant (20 PFU per cell) and proteaseAcNPV recombinant (10 PFU per cell). In panel a, the cells expressed the $\mathrm{N}$-myristylated versions of WT $\left(\mathrm{Gag} 12 \mathrm{myr}^{+}\right)$or insertion mutant Pr55 $5^{\text {Gag; }}$ in panel $b$, cells expressed the non-N-myristylated versions. Cells were harvested at $24 \mathrm{~h}$ p.i., and cell lysates were analyzed by SDS-PAGE and immunoblotting with rabbit polyclonal anti-Gag antibody. Note the difference in the cleavage patterns between in $209 \mathrm{myr}^{+}$and in $209 \mathrm{myr}^{-}$and between in $241 \mathrm{myr}^{+}$and in $241 \mathrm{myr}^{-}$. Sizes are indicated in kilodaltons.

with a higher efficiency by HIV-1 protease than the non-Nmyristylated forms were (compare Fig. 1a and b). This might be due to conformational differences between GagPr55myr ${ }^{+}$ and GagPr55myr ${ }^{-}$, resulting in a preferential cleavage of the $\mathrm{GagPr} 5 \mathrm{myr}^{+}$substrate at the MA-CA and CA-NC junction sites, to a colocalization of protease and $\mathrm{GagPr} 55 \mathrm{myr}^{+}$within the cell, or both. The first hypothesis was supported by the observation that in 209 and in 241 showed significantly different cleavage patterns in their $\mathrm{N}$-myristylated and non- $\mathrm{N}$-myristylated configurations (Fig. 1).

Assembly and budding of N-myristylated Pr55 ${ }^{\text {Gag }}$ mutants. Release of Gag virus-like particles by budding from the plasma membrane was qualitatively analyzed by EM of cell samples harvested at $48 \mathrm{~h}$ p.i. The EM patterns of $\mathrm{N}$-myristylated mutants of Pr55 ${ }^{\mathrm{Gag}}$ could be arranged into four groups. Group I corresponded to mutants with a WT budding pattern, as shown by parental recombinant Gag $12 \mathrm{myr}^{+}$, and comprised in $100 \mathrm{myr}^{+}$, in $120 \mathrm{myr}^{+}$, in $143 \mathrm{myr}^{+}$, in $184 \mathrm{myr}^{+}$, in $341 \mathrm{myr}^{+}$, in $374 \mathrm{myr}^{+}$, in $426 \mathrm{myr}^{+}$, in $438 \mathrm{myr}^{+}$, and in $462 \mathrm{myr}^{+}$. Four budding-defective mutants, in $40 \mathrm{myr}^{+}$, in $209 \mathrm{myr}^{+}$, in $241 \mathrm{myr}^{+}$, and 
in $334 \mathrm{myr}^{+}$, constituted group II. Group III consisted of mutants, represented by in $438 \mathrm{myr}^{+}$, which differed from the parental type in the cellular sublocation of Gag particles. One particular mutant, in $357 \mathrm{myr}^{+}$, which showed budding particles with abnormal size and shape, was assigned to a single group, group IV. Figure 2 illustrates these patterns for some members of the four groups.

Mutant in374myr ${ }^{+}$(group I) showed budding Gag particles indistinguishable from the WT (Fig. 2a), whereas in $357 \mathrm{myr}^{+}$ (group IV) released budding particles heterogeneous in size and shape, with many particles having a diameter smaller than that released by WT Gag12myr ${ }^{+}, 70 \mathrm{~nm}$ versus 120 to $130 \mathrm{~nm}$ (Fig. 2c). Among the group II mutants, which were completely defective in budding, in $209 \mathrm{myr}^{+}$provoked profound alterations of the cell surface, with indentations and local disruptions of the plasma membrane, suggesting an increased rigidity of the membranal bilayer compared with parental Gag-expressing cells (Fig. 2d and e). This was reminiscent of the EM pattern shown by a frameshift mutant of Gag-Pol expressed in insect cells and accumulating a C-truncated $90-\mathrm{kDa}$ fusion protein (20). Three mutants, in $40 \mathrm{myr}^{+}$, in $357 \mathrm{myr}^{+}$, and in $438 \mathrm{myr}^{+}$, insertions of which were localized in different areas of the $\operatorname{Pr} 55^{\mathrm{Gag}}$ sequence, shared properties with members of different groups, suggesting that the same insertion could have pleiotropic effects. For example, membrane-enveloped Gag particles assembled by in $438 \mathrm{myr}^{+}$and by in $357 \mathrm{myr}^{+}$were rarely found at the cell surface (as for the group I members) but preferentially accumulated within intracytoplasmic vesicles (Fig. 2b). On the other hand, in $40 \mathrm{myr}^{+}$, which failed to release budding particles from the plasma membrane (as for the group II members), assembled some Gag particles of 65 to $70 \mathrm{~nm}$ in diameter within the cytoplasm (not shown). These particles did not react with anti-p17 antibody in immunoelectron microscopy but reacted with anti-p6 antibody (not shown). This observation, and the rapid cleavage of in $40-\mathrm{GagPr} 55$ by cellular proteases at the p17-p24 junction, suggested that the 39-kDa Gag product, containing the p24 and p15 domains, could assemble intracellularly into small core-like particles.

Intracellular assembly and nuclear localization of non-Nmyristylated Pr55 ${ }^{\mathrm{Gag}}$ mutants. In insect cells infected by recombinant baculovirus expressing non-N-myristylated fulllength Gag precursor, we have shown that Gag particles were massively accumulated in the nucleus, in contrast to p6-deleted mutant of Pr55 Gag, which mainly assembled Gag particles in the cytoplasm (34). This finding suggested that some nuclear targeting function was directly or indirectly associated with the p6 domain. EM observation of cells infected by non-N-myristylated parental G2A clone and by each of our 14 insertion mutants showed that in general, the non- $\mathrm{N}$-myristylated insertion mutants formed significantly less core-like structures than did parental G2A Gag within the nucleus (34) and that most of the intranuclear Gag material accumulated as amorphous inclusions. The phenotypic groups previously defined for the $\mathrm{N}$-myristylated Gag family were tentatively applied to the non-N-myristylated versions of mutant Pr55 Gag. However, no mutant showed any particles resembling the intranuclear Gag cores assembled by parental G2A and could thus be individualized as group I. Assembly-defective mutants (group II) comprised two mutants, in $100 \mathrm{myr}^{-}$and in $334 \mathrm{myr}^{-}$. Group III was a heterogeneous group, characterized by a variety of Gag topological patterns differing from that of the parental recombinant G2A. Four of them, in 374 $\mathrm{myr}^{-}$, in $426 \mathrm{myr}^{-}$, in $438 \mathrm{myr}^{-}$, and in $462 \mathrm{myr}^{-}$, exhibited rare particles within the cytoplasm and none in the nucleus (Fig. 2h). One mutant, in $209 \mathrm{myr}^{-}$, assembled particles which budded inside the perinuclear cisterna, but none were detected within the nucleoplasm (Fig. 2f).
Group IV consisted of mutants showing amorphous intranuclear inclusions of Gag material, with rare or no individualized core particles. This was the case for in $40 \mathrm{myr}^{-}$, in $120 \mathrm{myr}^{-}$, in $143 \mathrm{myr}^{-}, \quad$ in $184 \mathrm{myr}^{-}$, in $241 \mathrm{myr}^{-}, \quad$ in $341 \mathrm{myr}^{-}$, and in $357 \mathrm{myr}^{-}$(Fig. 2g). Taken together, the EM observations suggested that most of our insertions were more detrimental to Gag assembly when expressed in the non- $\mathrm{N}$-myristylated context than in the N-myristylated context of Pr55 ${ }^{\mathrm{Gag}}$.

Extracellular release of mutant Gag precursors. N-myristylated Gag precursor has been shown to be released into the culture medium of recombinant-infected insect cells as soluble Gag polyproteins and membrane-enveloped budding particles, whereas non-N-myristylated Gag precursor is released only as unassembled, soluble material (35). The amount of extracellular Gag precursor secreted in particulate form was quantitatively estimated by SDS-PAGE and chemiluminescent protein blotting analysis of aliquots of Gag particle pellets isolated from cell culture media. The same assay was used to quantitate the total Gag secretion in aliquots of unfractionated cell culture media. Particulate Gag represented 70 to $85 \%$ of the total WT Pr55 ${ }^{\mathrm{Gag}}$ secreted by Gag12 $\mathrm{myr}^{+}$-infected cells. Extracellular release of both particulate and soluble Gag was almost totally abolished in in $40 \mathrm{myr}^{+}$, a result consistent with the loss of the $\mathrm{N}$-myristylated p17 domain of Gag precursor. This result suggested that the p39 Gag product (p24-p15) was not secreted at detectable levels by Sf 9 cells. With the exception of three mutants, in $426 \mathrm{myr}^{+}$, in $438 \mathrm{myr}^{+}$, and in $462 \mathrm{myr}^{+}$, which were slightly reduced in Gag particle release compared with the WT, all insertions were detrimental to some extent to the secretion of particulate Gag (Fig. 3a). The histogram of Gag particle concentration in the media at $48 \mathrm{~h}$ p.i. showed that the maximum effect occurred for insertion mutants within positions 143 to 374 , i.e., a region overlapping virtually the entire CA domain (Fig. 3a). This result confirmed previous observations that mutations in the CA domain are particularly critical for virion assembly $(10,16,36,44)$.

When the culture supernatants were assayed for total Gag (particulate plus soluble), the region between residues 209 and 334 appeared to be critical for secretion of N-myristylated Gag precursor (Fig. 3a). These results confirmed the EM analyses, in which no particles were found budding from the plasma membrane of cells infected by in $209 \mathrm{myr}^{+}$, in $241 \mathrm{myr}^{+}$, and in $334 \mathrm{myr}^{+}$at $48 \mathrm{~h}$ p.i. (Fig. 2). However, for five mutants, in $143 \mathrm{myr}^{+}, \quad$ in $184 \mathrm{myr}^{+}$, in $341 \mathrm{myr}^{+}, \quad$ in $357 \mathrm{myr}^{+}$, and in $374 \mathrm{myr}^{+}$, the amounts of total Gag secreted represented 5 to 10 times the amounts of particulate Gag, suggesting a higher efficiency of soluble Pr55 ${ }^{\mathrm{Gag}}$ secretion compared with WT (Fig. 3a).

Total Pr55 ${ }^{\mathrm{Gag}}$ assayed in the culture supernatants of non-Nmyristylated recombinant-infected cells represented nonenveloped, soluble Gag polyproteins (35). The critical domain for secretion of soluble non-N-myristylated Pr55 $5^{\text {Gag }}$ coincided with the region responsible for the secretion-defective phenotype of N-myristylated Gag, although spanning a narrower sequence, between residues 209 and 241 (Fig. 3b). On each boundary of this region, some insertion mutants secreted soluble non-N-myristylated Gag with a higher efficiency than the parental recombinant G2A. This was the case for in $184 \mathrm{myr}^{-}$, in $334 \mathrm{myr}^{-}$, in 341 $\mathrm{myr}^{-}$, and in $357 \mathrm{myr}^{-}$(Fig. 3b).

Viral RNA binding. The capacity of WT and mutant Pr55 Gag to bind to viral RNA was investigated by Northwestern blotting assay (26) of WT- and mutant-infected cell extracts analyzed by SDS-PAGE. The viral RNA probe used contained the encapsidation signal psi of the RNA genome $(7,17,24)$. In both $\mathrm{N}$-myristylated and non-N-myristylated Gag autoradio- 

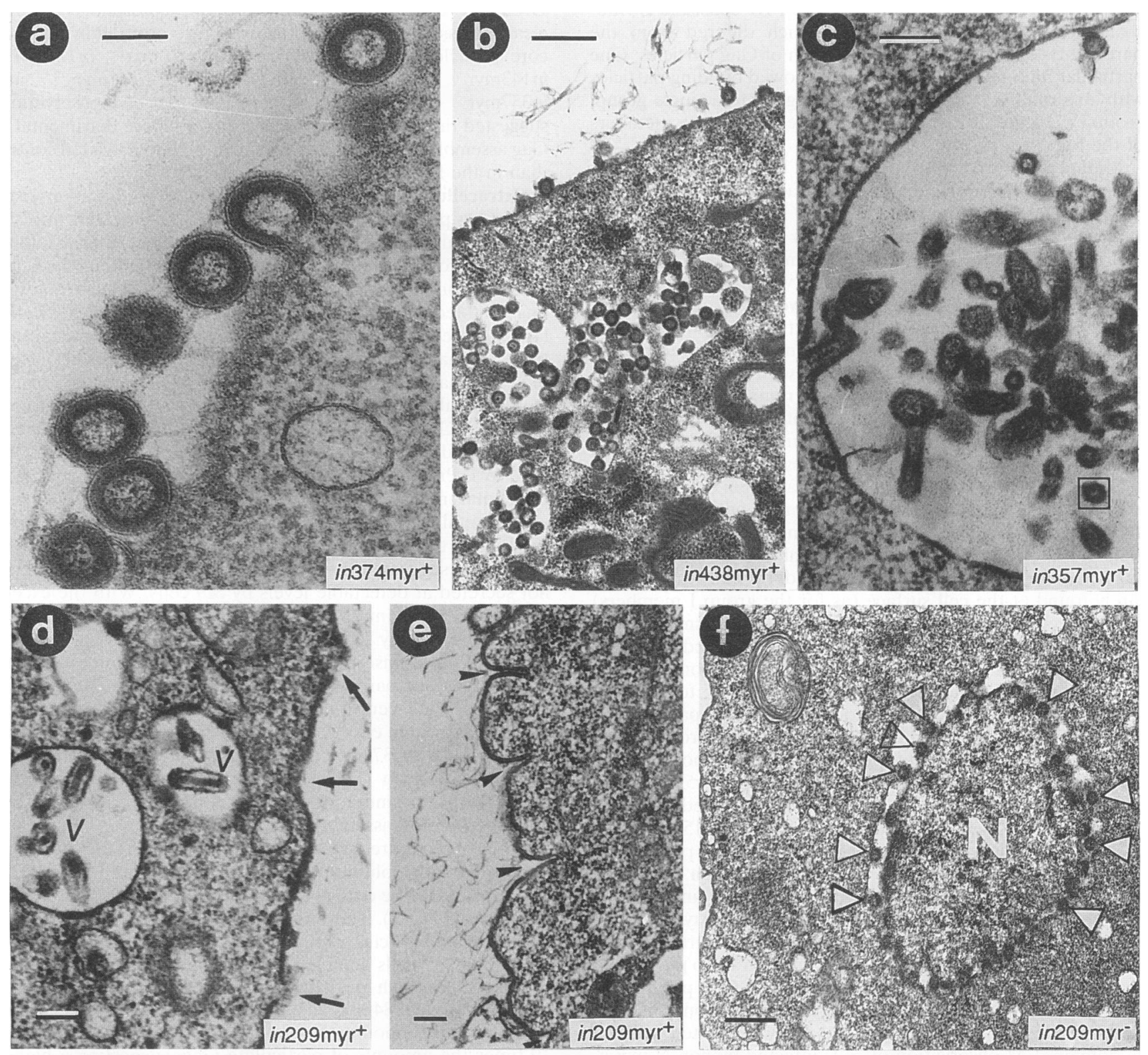

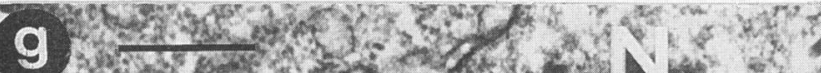
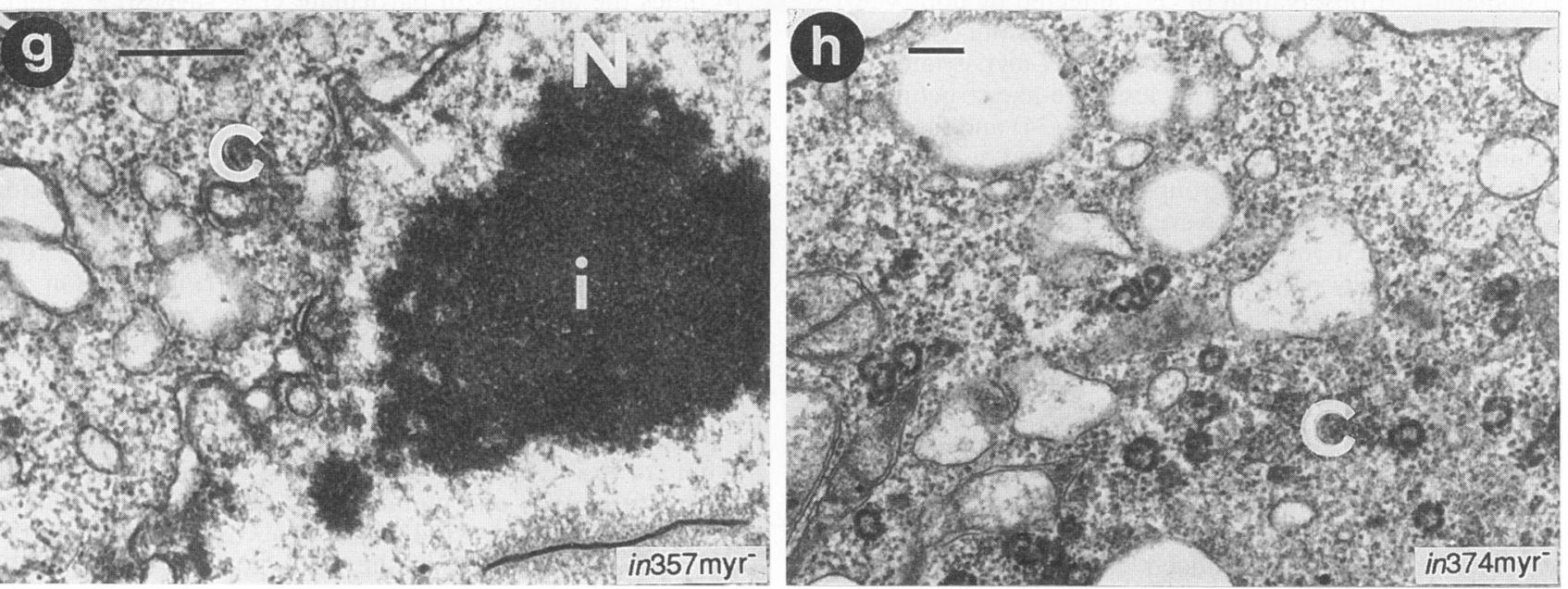
FIG. 2. EM analysis of Sf9 cells expressing N-myristylated and non-N-myristylated insertion mutants of recombinant Pr55 ${ }^{\text {Gag }}$. Arrows in panel $\mathrm{d}$ show local disruptions of the plasma membrane. Arrowheads in panel e point to plasma membrane indentations. Open arrowheads in panel $\mathrm{f}$ point to Gag core-like particles budding in the perinuclear cisterna. Note the accumulation of Gag particles (120 to $130 \mathrm{~nm}$ in diameter) in vesicles of in 438myr ${ }^{+}$-infected cells (b) and the heterogeneity in shape and diameter (65 to $70 \mathrm{~nm}$ for the boxed particle) of intravesicular particles in in $357 \mathrm{myr}^{+}$-infected cells (c). V, virions of AcNPV; C, cytoplasm; N, nucleus; i, inclusion. Bars represent $100 \mathrm{~nm}(\mathrm{a}), 200 \mathrm{~nm}$ (c, d, e, g, and h), and $500 \mathrm{~nm}$ (b and $\mathrm{f})$.

grams, no radioactivity was detected at the position of $\mathrm{Pr} 55^{\mathrm{Gag}}$ for in $40 \mathrm{myr}^{+}$and in $40 \mathrm{myr}^{-}$, but a major signal was visible at $39 \mathrm{kDa}$ (Fig. 4b and d). The same 39-kDa band was found in the WT and most of the mutant Gag patterns, and this was likely to represent a spontaneous cleavage product of the Gag precursor, consisting of the p24 capsid and p15 nucleocapsid domains. In their non-N-myristylated configuration, all mutant
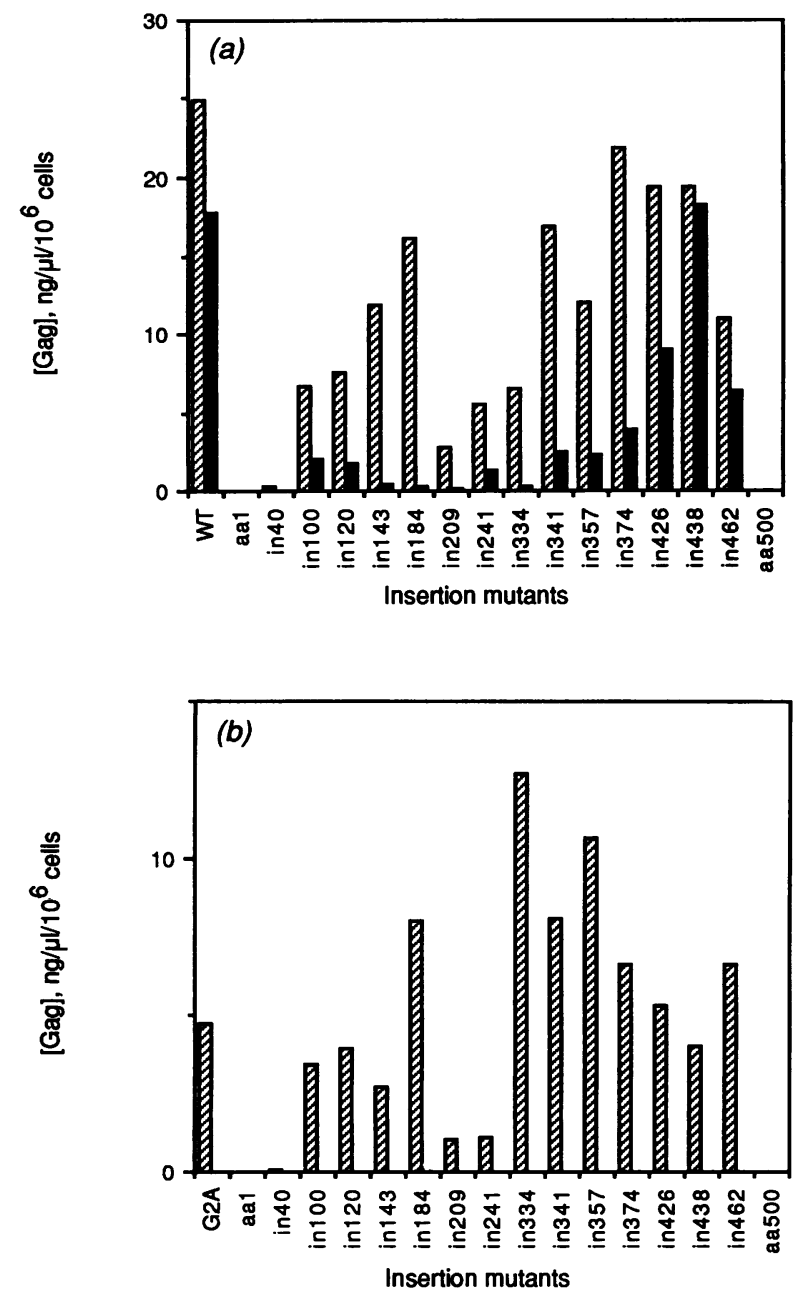

FIG. 3. Extracellular release of WT and insertion mutants of Pr55 ${ }^{\mathrm{Gag}}$ by Sf 9 cells. Aliquots of medium from cell cultures expressing $\mathrm{N}$-myristylated (a) or non-N-myristylated (b) $\mathrm{Pr} 55^{\mathrm{Gag}}$ were withdrawn at $48 \mathrm{~h}$ p.i. and assayed for secretion of total (particulate plus soluble) Pr55 ${ }^{\mathrm{Gag}}$ (hatched columns) and for budding and release of membraneenveloped Gag particles (filled columns). Gag secretion was expressed as the concentration of Pr55 $5^{\mathrm{Gag}}$ in the culture medium. Standard deviation was 10 to $15 \%$ of the reported value $(n=3)$. The insertions are positioned on the linear sequence of the Gag precursor (amino acids 1 to 500), represented by the $x$ axis.
Pr55 ${ }^{\text {Gag }}$ other than in $40 \mathrm{myr}^{-}$bound to the viral RNA probe with similar efficiency (Fig. 4d). In their N-myristylated configuration, however, four mutants, besides in $40 \mathrm{myr}^{+}$, showed no detectable RNA binding activity of Pr55 Gag (Fig. 4b). Among the five mutations analyzed, three (in $40 \mathrm{myr}^{+}$, in $100 \mathrm{myr}^{+}$, and in $120 \mathrm{myr}^{+}$) were located in the $\mathrm{p} 17$ domain, one $\left(\right.$ in $\left.143 \mathrm{myr}^{+}\right)$was near the p17-p24 junction, and one (in $209 \mathrm{myr}^{+}$) was in the N-terminal third of the CA domain. This suggested that domains other than the p15 nucleocapsid contributed significantly to the RNA binding of the full-length Gag precursor in the Northwestern blotting assay. To further analyze the role of C-terminal regions of the Gag precursor in RNA binding, C-truncated forms of $\mathrm{Gag}$ in both their $\mathrm{N}$ myristylated and non- $\mathrm{N}$-myristylated versions were also assayed by Northwestern blotting. The deletion mutants used were Pr47 ${ }^{\mathrm{Gag}}$ (p6 deleted), Pr41 ${ }^{\mathrm{Gag}}$ (p15 deleted), and Och184, a 22-kDa N-terminal Gag product consisting of the entire matrix domain and the first 50 amino acids from the capsid. As shown in Fig. 4, Och184 and Pr41 ${ }^{\text {Gag }}$ did not bind to the genomic probe in either their $\mathrm{N}$-myristylated or non- $\mathrm{N}$-myristylated configuration, whereas p6-deleted $\operatorname{Pr} 47^{\mathrm{Gag}}$ bound to RNA with the same efficiency regardless of whether the myristyl group was present at its $\mathrm{N}$ terminus. This finding confirmed previous observations on the RNA binding function of the $\mathrm{p} 7$ nucleocapsid domain $(9,21)$.

However, the binding patterns shown by some of our insertion mutants implied a key role of the N-terminal moiety of Gag precursor in this function. This role would function only in the presence of the $\mathrm{p} 6$ domain, as inferred from the results obtained with N-myristylated and non-N-myristylated Pr47 4 Gag (Fig. 4). The difference observed in the Northwestern blotting assay between the $\mathrm{N}$-myristylated mutants in $100 \mathrm{myr}^{+}$, in $120 \mathrm{myr}^{+}$, in $143 \mathrm{myr}^{+}$, and in $209 \mathrm{myr}^{+}$on one hand and their non-N-myristylated counterparts in $100 \mathrm{myr}^{-}$, in $120 \mathrm{myr}^{-}$, in $143 \mathrm{myr}^{-}$, and in $209 \mathrm{myr}^{-}$on the other hand suggested that the RNA binding capacity of Pr55 Gag could be both sequence and conformation dependent. In this hypothesis, the accessibility and binding efficiency of the RNA recognition sequence(s) in the $\mathrm{p} 7$ nucleocapsid domain would be significantly influenced by other upstream domains, located between residues 100 and 120 in the matrix and between positions 143 and 209 in the capsid.

Complementation and transdominance. Sf 9 cells were coinfected pairwise with the N-myristylated mutants, and extracellular Pr55 ${ }^{\mathrm{Gag}}$ was assayed in the cell culture supernatants for eventual complementation and rescue or, alternatively, negative transdominant effect on Gag budding and secretion. Table 2 shows the results of the complementation assays, performed on supernatant of cell cultures simultaneously infected by two recombinants. There was some complementation effect for Gag secretion in coinfections involving in $374 \mathrm{myr}^{+}$and in $426 \mathrm{myr}^{+}$, but most of the coinfected cells yielded less extracellular Gag than single WT recombinant-infected cells did. In most of the coinfections involving in $40 \mathrm{myr}^{+}$or in $120 \mathrm{myr}^{+}$as one of the pairs, a significantly lower Gag secretion was observed. A similar effect was observed with many pairs involving in $209 \mathrm{myr}^{+}$. 
(a)

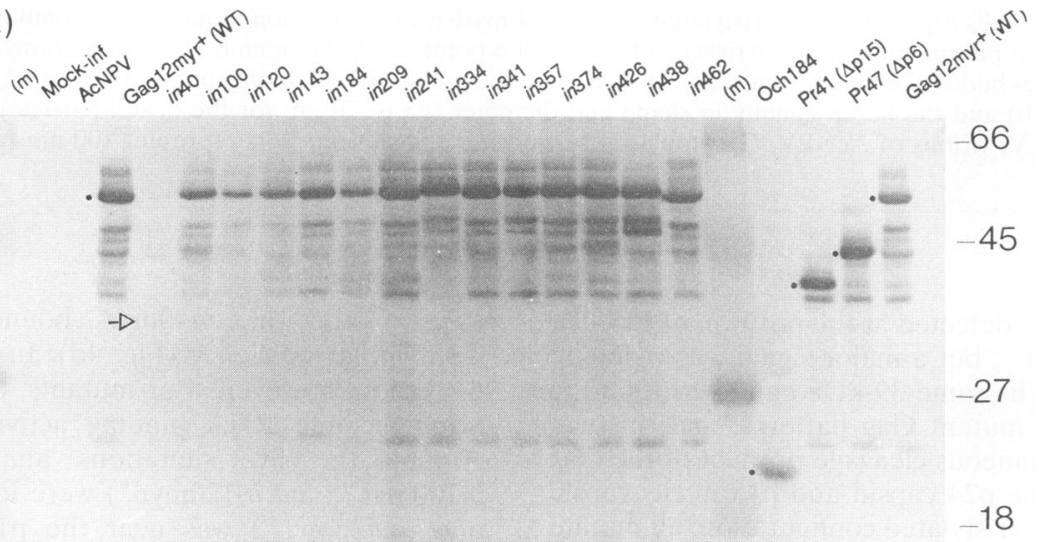

(b)
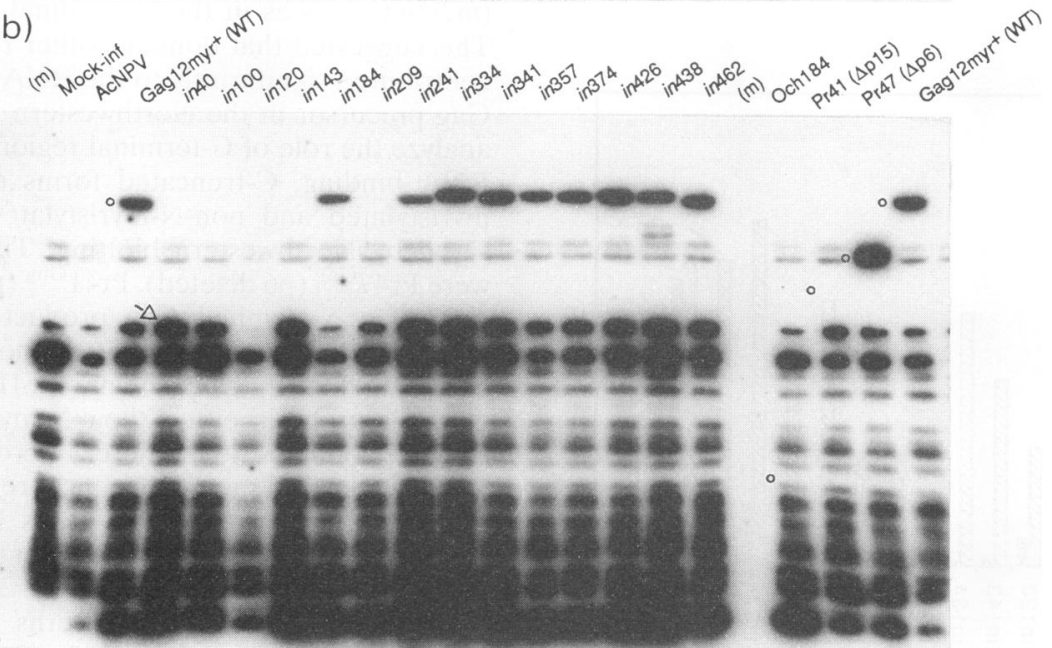

(c)

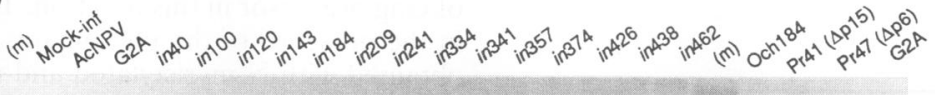

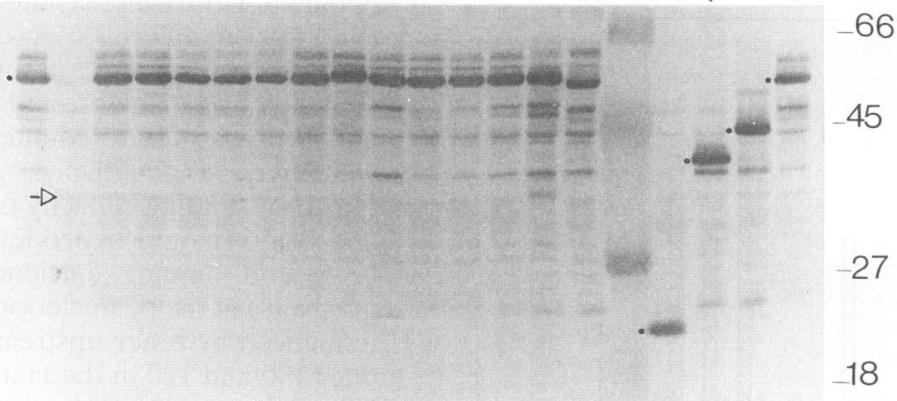

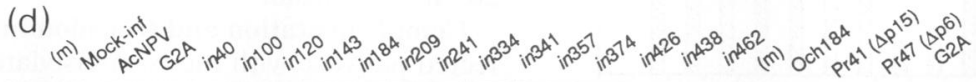

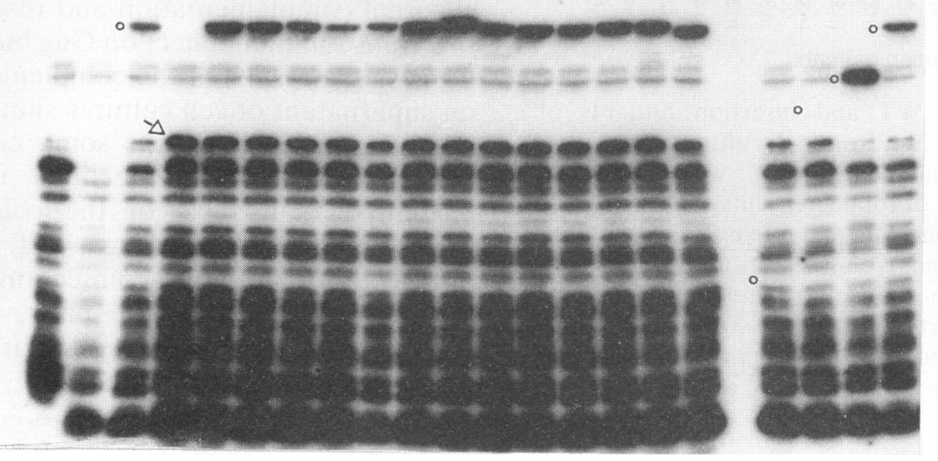


TABLE 2. Complementation for Gag secretion between N-myristylated insertion mutants ${ }^{a}$

\begin{tabular}{|c|c|c|c|c|c|c|c|c|c|c|c|c|c|c|c|}
\hline & WT & in 40 & in 100 & in 120 & in 143 & in 184 & in 209 & in 241 & in 334 & in 341 & in 357 & in 374 & in 426 & in 438 & in 462 \\
\hline WT & 100 & 79 & 59 & 67 & 71 & 52 & 53 & 72 & 67 & 72 & 83 & 66 & 96 & 73 & 81 \\
\hline in 40 & & $\leq 1$ & 4 & 13 & 16 & 16 & 22 & 30 & $\leq 1$ & 26 & 25 & 16 & 46 & 22 & 46 \\
\hline in 100 & & & 31 & 43 & 42 & 29 & 62 & 77 & 39 & 33 & 28 & 110 & 91 & 70 & 43 \\
\hline in 120 & & & & 31 & 20 & 17 & 10 & 17 & 12 & 26 & 12 & 45 & 33 & 24 & 25 \\
\hline in 143 & & & & & 42 & 25 & 44 & 36 & 19 & 16 & 14 & 27 & 37 & 41 & 36 \\
\hline in 184 & & & & & & 65 & 46 & 56 & 27 & 53 & 40 & 69 & 82 & 68 & 49 \\
\hline in 209 & & & & & & & 23 & 18 & 13 & 13 & 3 & 6 & 21 & 32 & 22 \\
\hline in 241 & & & & & & & & 19 & 20 & 44 & 65 & 97 & 91 & 68 & 74 \\
\hline in 334 & & & & & & & & & 23 & 19 & 21 & 53 & 24 & 13 & 75 \\
\hline in 341 & & & & & & & & & & 69 & 56 & 92 & 75 & 66 & 59 \\
\hline in 357 & & & & & & & & & & & 49 & 53 & 75 & 61 & 40 \\
\hline in 374 & & & & & & & & & & & & 92 & 77 & 50 & 60 \\
\hline in 426 & & & & & & & & & & & & & 78 & 68 & 59 \\
\hline in 438 & & & & & & & & & & & & & & 77 & 66 \\
\hline in 462 & & & & & & & & & & & & & & & 45 \\
\hline
\end{tabular}

"Sf9 cells were coinfected with the same MOI of each Gag recombinant ( 15 PFU per cell), and culture supernatants were assayed for Pr55 ${ }^{\text {(jag }}$ secretion at 48 h p.i. Results are expressed as a percentage of WT Pr55 Gatg secreted by Gag12 myr ${ }^{+}$. Standard deviation represented 10 to $15 \%$ of the reported values (average of three determinations).

The transdominant negative effect on Gag secretion exerted by Gag mutants over the WT Gag was further analyzed by preinfecting the cells with each of the mutants $1 \mathrm{~h}$ before adding the WT Gag12 $\mathrm{myr}^{+}$inoculum. No drastic effect was observed when preinfections were performed with recombinants expressing the $\mathrm{N}$-myristylated version of the GagPr55 mutants, and only a slight decrease in Gag secretion was observed for insertions located in a large region of Pr $55^{\mathrm{Gag}}$ overlapping the matrix and most of the capsid domain, until position 334 (Fig. 5, hatched columns). However, preexpression of non-N-myristylated, budding-defective insertion mutants resulted in a significant reduction of Gag secretion for some mutations located in two domains, the matrix and the nucleocapsid (Fig. 5, filled columns). The magnitude of the effect ranged from 5-fold with in $100 \mathrm{myr}^{-}$, in $120 \mathrm{myr}^{-}$, in $426 \mathrm{myr}^{-}$, and in $438 \mathrm{myr}^{-}$to 10 -fold with in $40 \mathrm{myr}^{-}$.

\section{DISCUSSION}

A panel of two sets of 14 insertion mutants of HIV-1 Gag, one set carrying the normal $\mathrm{N}$-myristylation signal and the other set constituting their non- $\mathrm{N}$-myristylated versions, was isolated and expressed in baculovirus-infected cells. The phenotypes of these mutants are summarized in Table 3 . The first picture which emerged from this phenotypic characterization was the essential role of the myristylated $\mathrm{N}$ terminus of Pr55 $5^{\mathrm{Gag}}$ in multiple biological functions, besides its role in membrane targeting and budding of Gag virus-like particles $(8$, $13,15,31,34,35)$. Three lines of experimental arguments suggested that this pleiotropic effect was mediated by an $\mathrm{N}$-myristyl-dependent conformation of GagPr55.

(i) Comparison studies of our two sets of insertion mutants suggested that the myristylated $\mathrm{N}$ terminus acted as a cisdominant signal overriding various assembly mutations in the Pr55 ${ }^{\mathrm{Gag}}$ sequence. Mutations in non-N-myristylated GagPr55 which were detrimental to self-assembly of Gag cores within the cell were rescued to almost WT budding levels in the $\mathrm{N}$-myristylated context. This was observed for insertions at positions $100,120,143,184,341,374,426,438$, and 462. A similar effect has been observed with p15-deleted, assemblydefective mutants of non-N-myristylated $\operatorname{Pr} 41^{\text {Gag }}$, in which the function of self-assembly and budding from the plasma membrane was restored upon myristylation of the $\mathrm{N}$-terminal residue $(21,34,35)$, and with an assembly-defective substitution mutant of Pr55 ${ }^{\text {Gag }}$, L322S, the assembly-defective phenotype of which was expressed only in the non-N-myristylated context (18). (ii) The processing of Pr55 Gag in vivo by HIV-1 protease coexpressed in trans was found to occur with different efficiency for $\mathrm{N}$-myristylated and non- $\mathrm{N}$-myristylated configurations of the same $\operatorname{Pr} 55^{\mathrm{Gag}}$ mutants, e.g., in $241 \mathrm{myr}^{+}$and in $241 \mathrm{myr}^{-}$, and in $209 \mathrm{myr}^{+}$and in $209 \mathrm{myr}^{-}$, respectively (Fig. 1). (iii) The binding of $\operatorname{Pr} 55^{\mathrm{Gag}}$ to a genomic RNA probe carrying the encapsidation signal $(7,17,24)$ was abolished for four $\mathrm{N}$-myristylated mutants $\left(\right.$ in $100 \mathrm{myr}^{+}$, in $120 \mathrm{myr}^{+}$, in $143 \mathrm{myr}^{+}$, and in $209 \mathrm{myr}^{+}$), whereas their non-N-myristylated counterparts showed a WT binding activity (Fig. 4 and Table 3 ). The deletion of the $\mathrm{N}$-myristylation signal at the $\mathrm{N}$ terminus of Pr55 $5^{\mathrm{Gag}}$ mutants restored their normal RNA binding activity and thus acted as a common second-site suppressor mutation (11) for insertions localized in two separate domains. Such a global suppressor effect of mutations localized in both the matrix (in $100 \mathrm{myr}^{-}$and in $120 \mathrm{myr}^{-}$) and the capsid (in $143 \mathrm{myr}^{-}$and in $209 \mathrm{myr}^{-}$) was likely to result from a conformational change of the $\mathrm{N}$-myristyl-deleted Pr $55^{\text {Gag }}$.

FIG. 4. Viral RNA binding analysis of parental and insertion mutants of Pr55 ${ }^{\text {Gag }}$, expressed in their N-myristylated (a and b) and non-N-myristylated (c and d) configurations. Mock-infected cells and cells infected with WT baculovirus (AcNPV) or AcNPV-Gag recombinants were harvested at $36 \mathrm{~h}$ p.i. After SDS-PAGE and electrical transfer to ECL membranes, proteins of cell lysates were analyzed by Western (a and c) and Northwestern (b and d) blotting, performed on the same membranes. In panels $a$ and $b$ are shown the blots after immunoreaction with anti-p17 MAb Epiclone 5003. The positions of the gag gene products Pr55, Pr47, Pr41, and Och184 are indicated by filled dots in Western blots and open dots in Northwestern blots. The position of the in 40 39-kDa primary gag gene product is indicated by an open arrowhead. The 39-kDa band is not shown by the anti-p17 MAb, only by polyclonal anti-Gag (see Fig. 1) or by anti-p24 and anti-p6 MAbs. Note the absence of specific

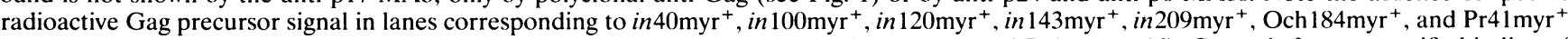

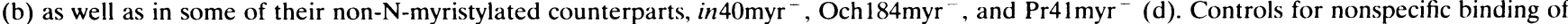
RNA are shown in lanes of mock-infected and WT baculovirus (AcNPV)-infected cell extracts. $(\mathrm{m})$, size markers. Sizes are indicated in kilodaltons. 
TABLE 3. Phenotype of GagPr55 insertion mutants ${ }^{a}$

\begin{tabular}{|c|c|c|c|c|c|}
\hline Recombinant Gag & $\begin{array}{l}\text { Extracellular } \\
\text { budding }\end{array}$ & $\begin{array}{l}\text { Cytoplasmic } \\
\text { assemblyc }\end{array}$ & $\begin{array}{c}\text { Nuclear } \\
\text { assembly }\end{array}$ & $\begin{array}{l}\text { Proteolytic } \\
\text { processing }^{d}\end{array}$ & $\begin{array}{l}\text { Binding to } \\
\text { vRNA probe }\end{array}$ \\
\hline Gag12myr ${ }^{+}(\mathrm{WT})$ & + & 0 & 0 & + & + \\
\hline in $40 \mathrm{myr}^{+}$(II, III) & $\boldsymbol{0}$ & $+/-g$ & $+1-h$ & $\mathbf{A}$ & $\boldsymbol{0}^{f}$ \\
\hline in $100 \mathrm{myr}^{+}$(I) & + & 0 & 0 & + & $\mathbf{0}$ \\
\hline in $120 \mathrm{myr}^{+}(\mathrm{I})$ & + & 0 & 0 & + & $\mathbf{0}$ \\
\hline in $143 \mathrm{myr}^{+}(\mathrm{I})$ & + & 0 & 0 & + & $\mathbf{0}$ \\
\hline in $184 \mathrm{myr}^{+}(\mathrm{I})$ & + & 0 & 0 & + & + \\
\hline in $209 \mathrm{myr}^{+}$(II) & $\mathbf{0}^{i}$ & 0 & 0 & $\mathbf{A}$ & $\mathbf{0}$ \\
\hline in $241 \mathrm{myr}^{+}$(II) & $\mathbf{0}$ & 0 & 0 & + & + \\
\hline in $334 \mathrm{myr}^{+}$(II) & $\mathbf{0}$ & 0 & 0 & + & + \\
\hline in $341 \mathrm{myr}^{+}(\mathrm{I})$ & + & 0 & 0 & + & + \\
\hline in $357 \mathrm{myr}^{+}$(III, IV) & $+^{g}$ & 0 & 0 & + & + \\
\hline in $374 \mathrm{myr}^{+}$(I) & + & 0 & 0 & + & + \\
\hline in $426 \mathrm{myr}^{+}$(I) & + & 0 & 0 & + & + \\
\hline in $438 \mathrm{myr}^{+}$(I, III) & + & $+/-^{j}$ & 0 & + & + \\
\hline in $462 \mathrm{myr}^{+}$(I) & + & 0 & 0 & + & + \\
\hline GagG2A (parental) & 0 & $+1-$ & + & + & + \\
\hline in $40 \mathrm{myr}^{-}$(IV) & 0 & 0 & $+1-^{h}$ & $\mathbf{A}$ & $\boldsymbol{0}^{f}$ \\
\hline in 100 $\mathrm{myr}^{-}$(II) & 0 & $\mathbf{0}$ & 0 & + & + \\
\hline in $120 \mathrm{myr}^{-}$(IV) & 0 & $+1-$ & $+1-^{h}$ & + & + \\
\hline in $143 \mathrm{myr}^{-}$(IV) & 0 & $+1-$ & $+/-^{h}$ & + & + \\
\hline in $184 \mathrm{myr}^{-}$(IV) & 0 & $+/-^{k}$ & $+/-^{h}$ & + & + \\
\hline in $209 \mathrm{myr}^{-}$(III) & 0 & $+1-^{l}$ & $\mathbf{0}$ & + & + \\
\hline in $241 \mathrm{myr}^{-}$(IV) & 0 & $\mathbf{0}$ & $+/-^{h}$ & $\mathbf{A}$ & + \\
\hline in334myr ${ }^{-}$(II) & 0 & 0 & 0 & + & + \\
\hline in $341 \mathrm{myr}^{-}$(IV) & 0 & $\mathbf{0}$ & $+/-^{h}$ & + & + \\
\hline in $357 \mathrm{myr}^{-}$(IV) & 0 & 0 & $+/-^{h}$ & + & + \\
\hline in $374 \mathrm{myr}^{-}$(III) & 0 & $+1-$ & 0 & + & + \\
\hline in $426 \mathrm{myr}^{-}$(III) & 0 & $+1-$ & $\mathbf{0}$ & + & + \\
\hline in $438 \mathrm{myr}^{-}$(III) & 0 & $+1-$ & $\mathbf{0}$ & + & + \\
\hline in $462 \mathrm{myr}^{-}$(III) & 0 & $+1-$ & 0 & + & + \\
\hline
\end{tabular}

${ }^{a}$ Each of the 14 insertion mutants was analyzed in both $\mathrm{N}$-myristylated and non-N-myristylated configurations. The roman numerals in parentheses correspond to the phenotypic groups for Gag particle assembly. Mutant patterns differing from the WT are indicated in boldface.

$b+$, occurrence of budding Gag particles; 0 , absence of particles visible under the EM. Quantification of extracellular release of Gag is shown in Fig. 3 .

${ }^{c}$ Symbols refer to the density of Gag particles per unit surface area of cytoplasm or nucleus on EM sections:,$+ \geq 3 / \mu \mathrm{m}^{2} ;+/-, 0.1$ to $1.0 / \mu \mathrm{m}^{2} ; 0$, not detected $(34)$.

${ }^{d}$ In vivo processing by HIV-1 protease was assayed by the occurrence of the specific p 25 -p 24 doublet, indicated by,+ resulting from the cleavage at the p17-p24, p24-p15, and p25-p15 junctions. Aberrant proteolytic pattern is indicated by A.

${ }^{e}$ Northwestern blotting analysis. +, WT binding pattern; 0, drastic decrease in the RNA binding capacity of Pr55 Gag, as shown in Fig. 5 .

${ }^{f}$ Premature cleavage at the p17-p24 junction and absence of further cleavage of the intermediate 39-kDa Gag product.

${ }^{g} \mathrm{Gag}$ particles of reduced diameter compared with WT Gag12 $\mathrm{myr}^{+}$(65 to $70 \mathrm{~nm}$ versus 120 to $130 \mathrm{~nm}$ ).

${ }^{h}$ Rare individualized Gag particles within or around amorphous inclusions.

${ }^{i}$ Indentations and fractures in rigid plasma membrane.

${ }^{j}$ Occurrence of numerous Gag particles within cytoplasmic vesicles.

${ }^{k}$ Clusters of Gag particles within cytoplasmic vesicles.

${ }^{l} \mathrm{Gag}$ particles budding into the perinuclear cisterna.

Our finding that mutations in the matrix domain could interfere with viral RNA binding was reminiscent of recent data showing an association between matrix protein and the HIV-1 RNA genome in vivo (5). The intracellular p17-RNA interactions, and the critical role of the $\mathrm{N}$-myristylated $\mathrm{p} 17$ domain in the conformational structure and physiology of full-length Gag precursor, could explain in part the requirement for a functionally intact matrix protein in the retrovirus capsid morphogenetic process $(32,33,45,46)$.

In the capsid domain of $\operatorname{Pr} 55^{\mathrm{Gag}}$, one particular region was found to be critical for the assembly process of Gag particles. Mutations spanning residues 209 to 334 in N-myristylated $\operatorname{Pr} 55^{\mathrm{Gag}}$ were found to be detrimental to the assembly and budding of membrane-enveloped Gag particles, and insertions located at positions 209 and 241 in non-N-myristylated Pr55 Gag negatively affected soluble Gag secretion. The same area has recently been shown to be critical for recognition and cleavage of Gag precursor by HIV-1 protease coexpressed in bacterial cells, probably via mutation-induced conformational modifications $(16,27)$. In addition, an insertion mutant at position 241 (R1509 [27]) has been found to be incapable of incorporating
Gag-Pol polyprotein within particles (31a), and a doubleserine insertion at the SpeI site (which overlaps the RsaI site used in our in 241 insertion) resulted in assembly of noninfectious Gag particles (43). Recent studies using substitution mutants in Pr55 ${ }^{\mathrm{Gag}}$ have also shown that positions 268 and 322 (18), 341 to 346 , and 350 to 352 (41) are essential for Gag assembly and particle formation. On the other hand, our results with mutants in $426 \mathrm{myr}^{+}$, in $438 \mathrm{myr}^{+}$, and in $462 \mathrm{myr}^{+}$ suggested that the nucleocapsid domain of Pr55 ${ }^{\mathrm{Gag}}$ was tolerant to a variety of mutations, confirming previous data $(1,43)$. Taken together, these data indicated that one crucial region for HIV-1 Gag precursor interactions and self-assembly consisted of the C-terminal moiety of the capsid domain $(1,10,36$, $43,44)$.

In simultaneous pairwise coinfections, three budding-defective mutants, in $40 \mathrm{myr}^{+}$, in $120 \mathrm{myr}^{+}$, and in $209 \mathrm{myr}^{+}$, appeared to exert some dominant negative effect on Gag secretion over most of the other insertion mutants (Table 2). In delayed coinfection experiments with WT and mutant Gag recombinants (Fig. 5), a negative effect in trans on the extracellular release of WT Pr55 ${ }^{\mathrm{Gag}}$ was found for insertions in two separate 


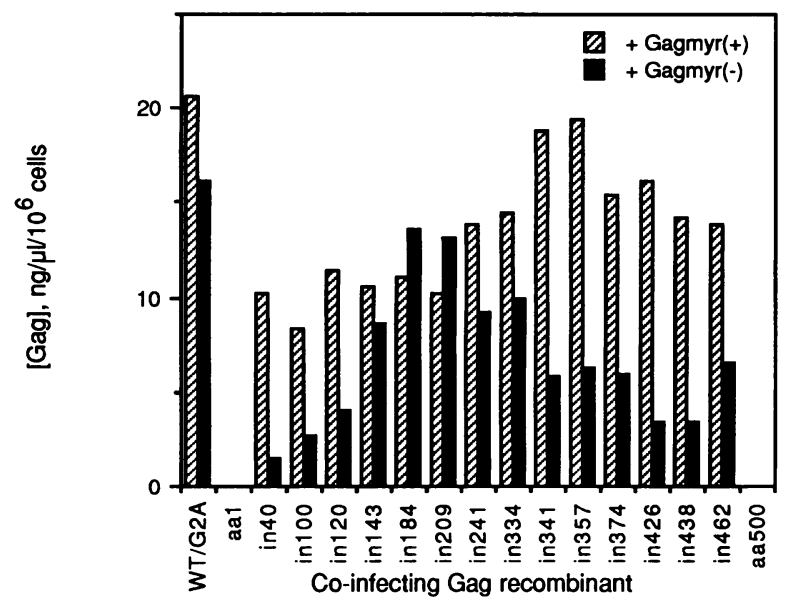

FIG. 5. Analysis of trans-dominant effects of insertion mutants on the secretion of WT Pr55 $5^{\mathrm{Gag}}$ by Gag $12 \mathrm{myr}^{+}$-infected cells. Sf 9 cells were preinfected with each Gag mutant $1 \mathrm{~h}$ prior to the addition of Gag $12 \mathrm{myr}^{+}$inoculum at the same MOI (15 PFU per cell). Total Gag secretion (particulate plus soluble Pr55 ${ }^{\text {Gag }}$ ) was expressed as the concentration of $\operatorname{Pr} 55^{\mathrm{Giag}}$ in the culture media. Standard deviation was 10 to $15 \%$ of the reported value $(n=3)$. Hatched columns, coinfections with $\mathrm{N}$-myristylated mutants; filled columns, coinfections with non- $\mathrm{N}$-myristylated mutants. The insertions are positioned on the linear sequence of the Gag precursor (amino acids 1 to 500), represented by the $x$ axis. The two leftmost columns correspond to control experiments using single Gag12 $\mathrm{myr}^{+}$-infected cells (hatched column) and cells preinfected with parental G2A $\left(\mathrm{myr}^{-}\right)$before Gag12myr ${ }^{+}$ (filled column).

regions of the Pr55 ${ }^{\mathrm{Gag}}$ sequence, the p17 MA (in 40, in 100 , and in 120) and the p7 NC (in 426 and in 438) domains. Insertions within the blunt restriction sites at positions 209 (A-209IAM-E) and 241 (S-241-IDA-T) in the HIV-1 gag sequence have been characterized as being two dominant mutations which negatively affected the cellular capacity to support HIV replication and release of WT virus (38). The result of our study with baculovirus-expressed Gag insertion mutants implied that at least for the insertion at position 209, the overall dominant effect on virus replication and release could in part involve some step in the capsid morphogenesis and budding of Gag particles from the plasma membrane. As suggested by our coinfection experiments, other regions within the matrix and nucleocapsid domains should be investigated for possible transdominant mutations with negative effect on self-assembly and extracellular release of Gag particles.

\section{ACKNOWLEDGMENTS}

N.C. and C.C. contributed equally to this work.

This work was supported by the Agence Nationale de Recherche sur le SIDA (ANRS-AC14), the Centre National de la Recherche Scientifique, and the Fondation pour la Recherche Médicale.

We express our gratitude to Renée Yew and Arnie Berk for helpful advice in handling the technology of suppressor-linker insertional mutagenesis and for the gift of plasmid pVSU-II and E. coli CC114. We acknowledge with much thanks the aid of Jeannette Tournier in the EM processing. We also thank M. G. Sarngadharan for providing the anti-p6 rat MAb, Monique Royer for her AcNPV-PR107 and AcNPV-PR77 recombinants, and Saw See Hong and Alise Reicin for fruitful discussions.

\section{REFERENCES}

1. Aldovini, A., and R. A. Young. 1990. Mutations of RNA and protein sequences involved in human immunodeficiency virus type
1 packaging result in production of noninfectious virus. J. Virol. 64:1920-1926.

2. Andreassen, H., H. Bohr, J. Bohr, S. Brunak, T. Bugge, R. M. J. Cotterill, C. Jacobsen, P. Kusk, B. Lautrup, S. B. Petersen, T. Særmark, and K. Ulrich. 1990. Analysis of the secondary structure of the human immunodeficiency virus (HIV) proteins p17, gp120, and gp41 by computer modeling based on neural network methods. J. Acquired Immune Defic. Syndr. 3:615-622.

3. Argos, P. 1989. A possible homology between immunodeficiency virus p24 core protein and picornaviral VP2 coat protein: prediction of HIV p24 antigenic sites. EMBO J. 8:779-785.

4. Blomberg, J., and P. Medstrand. 1990. A sequence in the carboxylic terminus of the HIV-1 matrix protein is highly similar to sequences in membrane-associated proteins of other RNA viruses: possible functional implications. New Biol. 2:1044-1046.

5. Bukrinskaya, A. G., G. K. Vorkunova, and Y. Y. Tentsov. 1992. HIV-1 matrix protein p17 resides in cell nuclei in association with genomic RNA. AIDS Res. Hum. Retroviruses 8:1795-1801.

6. Cann, A. J., and J. Karn. 1989. Molecular virology of HIV: new insights into the virus life-cycle. AIDS 3(Suppl. 1):S19-S34.

7. Clavel, F., and J. M. Orenstein. 1990. A mutant of human immunodeficiency virus with reduced RNA packaging and abnormal particle morphology. J. Virol. 64:5230-5234.

8. Delchambre, M., D. Gheysen, D. Thines, C. Thiriart, E. Jacobs, E. Verdin, M. Horth, A. Burny, and F. Bex. 1989. The GAG precursor of simian immunodeficiency virus assembles into viruslike particles. EMBO J. 8:2653-2660.

9. De Rocquigny, H., C. Gabus, A. Vincent, M. C. Fournié-Zaluski, B. Roques, and J. L. Darlix. 1992. Viral RNA annealing activities of human immunodeficiency virus type 1 nucleocapsid protein require only peptide domain outside the zinc fingers. Proc. Natl. Acad. Sci. USA 89:6472-6476.

10. Ehrlich, L. S., B. E. Agresta, and C. A. Carter. 1992. Assembly of recombinant human immunodeficiency virus type 1 capsid protein in vitro. J. Virol. 66:4874-4883.

11. Fane, B., R. Villafane, A. Mitraki, and J. King. 1991. Identification of global suppressors for temperature-sensitive folding mutations of the P22 tailspike protein. J. Biol. Chem. 261:11640-11648.

12. Gelderblom, H. R. 1991. Assembly and morphology of HIV: potential effect of structure on viral function. AIDS 5:617-638.

13. Gheysen, D., E. Jacobs, F. de Foresta, C. Thiriart, M. Francotte, D. Thines, and M. De Wilde. 1989. Assembly and release of HIV-1 precursor Pr55gag virus-like particles from recombinant baculovirus-infected insect cells. Cell 59:103-112.

14. Göttlinger, H. G., T. Dorfman, J. G. Sodroski, and W. A. Haseltine. 1991. Effect of mutations affecting the p6 gag protein on human immunodeficiency virus particle release. Proc. Natl. Acad. Sci. USA 88:3195-3199.

15. Göttlinger, H. G., J. G. Sodroski, and W. A. Haseltine. 1989. Role of capsid precursor processing and myristoylation in morphogenesis and infectivity of human immunodeficiency virus type 1. Proc. Natl. Acad. Sci. USA 86:5781-5785.

16. Hansen, M., L. Jelinkek, S. Whiting, and E. Barklis. 1990 Transport and assembly of gag proteins into Moloney murine leukemia virus. J. Virol. 64:5306-5316.

17. Hayashi, T., T. Shioda, Y. Iwakura, and H. Shibuta. 1992. RNA packaging signal of human immunodeficiency virus type 1. Virology 188:590-599.

18. Hong, S. S., and P. Boulanger. 1993. Assembly-defective point mutants of the immunodeficiency virus type $1 \mathrm{Gag}$ precursor phenotypically expressed in recombinant baculovirus-infected cells. J. Virol. 67:2787-2798.

19. Hoshikawa, N., A. Kojima, A. Yasuda, E. Takayashiki, S. Masuko, J. Chiba, T. Sata, and T. Kurata. 1991. Role of the gag and pol genes of human immunodeficiency virus in the morphogenesis and maturation of retrovirus-like particles expressed by recombinant vaccinia virus: an ultrastructural study. J. Gen. Virol. 72:2509_ 2517

20. Hughes, B. P., T. F. Booth, A. S. Belyaev, D. McIlroy, J. Jowett, and P. Roy. 1993. Morphogenic capabilities of human immunodeficiency virus type $1 \mathrm{gag}$ and gag-pol proteins in insect cells. Virology 193:242-255.

21. Jowett, J. B. M., D. J. Hockley, M. V. Nermut, and I. M. Jones. 
1992. Distinct signals in HIV-1 Pr55 necessary for RNA binding and particle formation. J. Gen. Virol. 73:3079-3086.

22. Laemmli, U. K. 1970. Cleavage of structural proteins during the assembly of the head of bacteriophage T4. Nature (London) 227:680-685.

23. Langedijk, J. P. M., J. J. Schalken, M. Tersmette, J. G. Huisman, and R. H. Meloen. 1990. Location of epitopes on the major core protein p24 of human immunodeficiency virus. J. Gen. Virol. 71:2609-2614.

24. Lever, A., H. Göttlinger, W. Haseltine, and J. Sodroski. 1989 Identification of a sequence required for efficient packaging of human immunodeficiency virus type 1 RNA into virions. J. Virol. 63:4085-4087.

25. Lobel, L. I., and S. P. Goff. 1984. Construction of mutants of Moloney murine leukemia virus by suppressor-linker insertional mutagenesis: positions of viable insertion mutations. Proc. Natl. Acad. Sci. USA 81:4149-4153.

26. Luban, J., and S. P. Goff. 1991. Binding of human immunodeficiency virus type 1 (HIV-1) RNA to recombinant HIV-1 gag polyprotein. J. Virol. 65:3203-3212.

27. Luban, J., C. Lee, and S. P. Goff. 1993. Effect of linker insertion mutations in the human immunodeficiency virus type 1 gag gene on activation of viral protease expressed in bacteria. J. Virol 67:3630-3634.

28. Mervis, R. J., N. Ahmad, E. P. Lillehoj, M. G. Raum, F. H. R. Salazar, H. W. Chan, and S. Venkatesan. 1988. The gag gene products of human immunodeficiency virus type 1: alignment within the gag open reading frame, identification of posttranslational modifications, and evidence for alternative gag precursors. J. Virol. 62:3993-4002.

29. Myers, G., J. A. Berzofsky, B. Kober, R. F. Smith, and G. N Pavlakis (ed.). 1991. Human retroviruses and AIDS 1991. A compilation and analysis of nucleic acid and amino acid sequences, May 1991, vol. II, p. 5-9. Theoretical Biology and Biophysics, Los Alamos National Laboratory, Los Alamos, N. Mex.

30. Overton, H. A., Y. Fuji, I. R. Price, and I. M. Jones. 1989. The protease and gag gene products of the human immunodeficiency virus: authentic cleavage and post-translational modification in an insect cell expression system. Virology 170:107-116.

31. Pal, R., M. S. Reitz, Jr., E. Tschachler, R. C. Gallo, M. G. Sarngadharan, and F. D. M. Veronese. 1990. Myristoylation of gag polyproteins of HIV-1 plays an important role in virus assembly. AIDS Res. Hum. Retroviruses 6:721-730.

31a.Reicin, A. Personal communication.

32. Rhee, S. S., and E. Hunter. 1990. A single amino acid substitution within the matrix protein of a type $\mathrm{D}$ retrovirus converts its morphogenesis to that of a type $\mathrm{C}$ retrovirus. Cell 63:77-86.
33. Rhee, S. S., and E. Hunter. 1991. Amino acid substitutions within the matrix protein of type D retroviruses affects assembly, transport and membrane association of a capsid. EMBO J. 10:535-546.

33a.Royer, M. Unpublished data.

34. Royer, M., M. Cerutti, B. Gay, S. S. Hong, G. Devauchelle, and P. Boulanger. 1991. Functional domains of HIV-1 gag-polyprotein expressed in baculovirus-infected cells. Virology 184:417-422.

35. Royer, M., S. S. Hong, B. Gay, M. Cerutti, and P. Boulanger. 1992. Expression and extracellular release of human immunodeficiency virus type $1 \mathrm{Gag}$ precursors by recombinant baculovirus-infected cells. J. Virol. 66:3230-3235.

36. Schwartzberg, P., J. Colicelli, M. L. Gordon, and S. P. Goff. 1984. Mutations in the gag gene of Moloney murine leukemia virus: effects on production of virions and reverse transcriptase. J. Virol. 49:918-924.

37. Sommerfelt, M. A., C. R. Roberts, and E. Hunter. 1993. Expression of simian type D retroviral (Mason-Pfizer monkey virus) capsids in insect cells using recombinant baculovirus. Virology 192:298-306.

38. Trono, D., M. B. Feinberg, and D. Baltimore. 1989. HIV-1 Gag mutants can dominantly interfere with the replication of the wild-type virus. Cell 59:113-120.

39. Valverde, V., P. Lemay, J. M. Masson, B. Gay, and P. Boulanger. 1992. Autoprocessing of HIV-1 protease precursor expressed in $E$. coli from a synthetic gene. J. Gen. Virol. 73:639-651.

40. Veronese, F. D. M., R. Rahman, T. D. Copeland, S. Oroszlan, R. C. Gallo, and M. G. Sarngadharan. 1987. Immunological and chemical analysis of p6, the carboxyl-terminal fragment of HIV p15. AIDS Res. Hum. Retroviruses 3:253-264.

41. Von Poblotzki, A., R. Wagner, M. Niedrig, G. Wanner, H. Wolf, and S. Modrow. 1993. Identification of a region in the Pr55 $5^{\text {ag }}$. polyprotein essential for HIV-1 particle formation. Virology 193: 981-985.

42. Wain-Hobson, S., P. Sonigo, O. Danos, S. Cole, and M. Alizon. 1985. Nucleotide sequence of the AIDS virus, LAV. Cell 40:9-17.

43. Wang, C.-T., and E. Barklis. 1993. Assembly, processing, and infectivity of human immunodeficiency virus type 1 Gag mutants. J. Virol. 67:4264-4273.

44. Wills, J. W., and R. C. Craven. 1991. Form, function, and use of retroviral gag proteins. AIDS 5:639-654.

45. Yu, X. F., Q. C. Yu, T. H. Lee, and M. Essex. 1992. The C terminus of human immunodeficiency virus type 1 matrix protein is involved in early steps of the virus life cycle. J. Virol. 66:5667-5670.

46. Yu, X. F., X. Yuan, Z. Matsuda, T. H. Lee, and M. Essex. 1992. The matrix protein of human immunodeficiency virus type 1 is required for incorporation of viral envelope protein into mature virions. J. Virol. 66:4966-4971. 